\title{
The Need for Evidence-Based, Spiritually Oriented Psychotherapies
}

\author{
P. Scott Richards \\ Brigham Young University - Provo, scott_richards@byu.edu \\ Everett L. Worthington Jr. \\ Virginia Commonwealth University
}

Follow this and additional works at: https://scholarsarchive.byu.edu/facpub

Part of the Student Counseling and Personnel Services Commons

\section{Original Publication Citation}

Richards, P. S., \& Worthington, E. L. Jr. (2010). The need for evidence-based, spiritually oriented psychotherapies. Professional Psychology: Research and Practice, 41, 363-370.

\section{BYU ScholarsArchive Citation}

Richards, P. Scott and Worthington, Everett L. Jr., "The Need for Evidence-Based, Spiritually Oriented Psychotherapies" (2010). Faculty Publications. 3845.

https://scholarsarchive.byu.edu/facpub/3845 


\title{
The Need for Evidence-Based, Spiritually Oriented Psychotherapies
}

\author{
P. Scott Richards \\ Brigham Young University
}

\author{
Everett L. Worthington, Jr. \\ Virginia Commonwealth University
}

\begin{abstract}
Despite a proliferation of spiritually oriented psychotherapies during the past 2 decades in the mental health professions, outcome research is lacking. In this present article, 6 published outcome reviews that shed light on the efficacy of these psychotherapies are discussed. Although there is general support for the efficacy of spiritually oriented treatment approaches, the data base is relatively small and has methodological limitations. Spiritually oriented cognitive approaches for religious clients with depression and anxiety meet evidencebased standards of efficacy. Several other spiritually oriented approaches are probably efficacious but need additional investigation. Methodological recommendations for improving the quality of future studies in this domain are made. Philosophically and methodologically pluralistic research strategies that do not reduce spiritual phenomena into a naturalistic and materialistic framework are recommended.
\end{abstract}

Keywords: psychotherapy, spiritual, evidence based, efficacy

The number of spiritually oriented psychotherapies described in the mainstream psychological literature has increased dramatically during the past two decades. These approaches encourage clinicians to use interventions that respect the healing potential of their clients' faith traditions and lead to psychological improvement (Richards \& Bergin, 2005; Sperry \& Shafranske, 2005). Specific spiritual practices or interventions that may be used during spiritually oriented psychotherapy include, for example, conducting a spiritual assessment, consulting with or referring to spiritual leaders, teaching spiritual concepts, encouraging forgiveness, discussing scriptures, teaching mindfulness meditation, encouraging contemplative meditation and prayer, conducting spiritual imagery, and praying privately for clients (Ball \& Goodyear, 1991; Richards \& Bergin, 2005).

Spiritual psychotherapies grounded in the theologies of both Western (theistic) and Eastern spiritual traditions have been described in the psychological literature, including Buddhist, Hindu, Christian, Jewish, Muslim, and ecumenical theistic approaches (e.g., Richards \& Bergin, 2004, 2005). Jungian, transpersonal, psychodynamic, cognitive, rational emotive behavior therapy, interpersonal, humanistic, and multicultural psychologies also have been integrated with spiritual perspectives and interventions (e.g., Sperry \& Shafranske, 2005).

This article was published Online First September 6, 2010.

P. SCOTT RichARDS received his $\mathrm{PhD}$ in counseling psychology from the University of Minnesota, Minneapolis. He currently teaches in the Department of Counseling Psychology at Brigham Young University. His areas of research interest include spiritual issues and interventions in psychotherapy and the role of spirituality in eating disorder treatment and recovery.

EVERETT L. Worthington, JR. received his PhD in psychology (counseling) from the University of Missouri-Columbia. He currently teaches in the Department of Psychology at Virginia Commonwealth University and is primarily affiliated with the counseling psychology program and secondarily affiliated with social psychology and developmental psychology programs. His research interests include forgiveness, couple counseling, and religious/spiritual issues and interventions.

CORRESPONDENCE CONCERNING THIS ARTICLE should be addressed to P. Scott Richards, Department of Counseling Psychology, Brigham Young University, Provo, UT 84602. E-mail: scott_richards@ byu.edu
Spiritual psychotherapies have been used most frequently in a treatment-tailoring fashion during individual psychotherapy with adult clients; however, they have also been used in group therapy, couple and family therapy, and child and adolescent therapy (Richards \& Bergin, 2005). Spiritual approaches and interventions also have been applied with many clinical issues, including depression, anxiety, addictions, eating disorders, stress, compulsive gambling, dissociative disorders, trauma, antisocial and psychopathic personality disorders, and postpartum depression. The recognition that religion and spirituality are important aspects of diversity has contributed to the use of spiritual treatment approaches with various multicultural and special client populations, including African Americans, Asian Americans, Latinos/Latinas, Native Americans, gays, lesbians, and bisexuals (American Psychological Association; APA, 2008; Richards \& Bergin, 2000).

Several survey studies of members of the APA (e.g., Raphel, 2001; Shafranske \& Malony, 1990; Shafranske, 2000), as well as studies of psychotherapists within specific faith traditions (e.g., Ball \& Goodyear, 1991; Richards \& Potts, 1995), have provided evidence that $30 \%$ to $90 \%$ of practitioners-depending on the group surveyed-incorporate spiritual interventions into their practices. Higher percentages of psychotherapists who are personally religious use spiritual interventions, compared to therapists who are less religious, and they tend to use a wider variety of such interventions, but surprising numbers of nonreligious psychotherapists also use them (Raphel, 2001; Shafranske, 2000). Most psychotherapists use spiritual approaches and interventions as part of an integrative approach that includes interventions from one or more of the mainstream secular therapeutic traditions (Richards \& Bergin, 2004, 2005; Sperry \& Shafranske, 2005; Worthington, Kurusu, McCullough, \& Sandage, 1996).

\section{Status of Outcome Research on Spiritually Oriented Psychotherapies}

Reviews of research have consistently concluded that, despite the presence of many spiritual treatments and interventions in the psychological literature and in psychotherapy, outcome research 
was scant. In 1996, Worthington, Kurusu, McCullough, and Sanders reviewed 148 empirical studies on religion and psychotherapy. Only eight were outcome studies. Since then, five more outcome reviews have been done, including McCullough's (1999) metaanalysis of five outcome studies; Worthington and Sandage's (2001) narrative review of nine outcome studies; Smith, Bartz, and Richards' (2007) meta-analysis of 31 outcome studies; Hook et al.'s (2010) narrative review that examined which spiritually oriented psychotherapies meet evidence-based criteria for efficacy and specificity; and finally, Worthington, Hook, Davis, and McDaniel's (in press) meta-analysis of 61 outcome studies. Because these reviews are pertinent to developing an evidencebase for spiritual psychotherapies, we briefly summarize their major findings and discuss the methodological limitations to date of outcome studies in this domain. We make recommendations for future studies about spiritual treatment approaches, including the need for (a) a methodologically pluralistic research strategy, (b) collaboration between researchers and practitioners, (c) assessment of religious and spiritual outcomes of psychotherapy, (d) attention to ethical issues and boundaries, and (e) openness to the investigation and discovery of spiritual influences in therapeutic change.

\section{Major Findings and Conclusions of Six Outcome Reviews}

Table 1 summarizes the major findings and conclusions of the six outcome reviews. The three meta-analysis reviews were consistent in providing quantitative support for the conclusion that spiritually oriented psychotherapies tend to be effective overall with effect sizes that range from .27 to .75 , depending on which studies were included in the analyses. These are comparable to effect sizes observed for many mainstream secular psychotherapy approaches (Wampold et al., 1997). Thus, the meta-analytic findings provide incentive for further use and empirical study of spiritually oriented psychotherapies.

The number of studies located has increased substantially since 1996 in which only eight studies could be found (and were methodologically weak) through the most recent meta-analysis in which 10 studies comparing secular and spiritually tailored treatments with random assignment were found. The numbers of studies using non-Christian oriented approaches and non-cognitive behavioral therapy (CBT) approaches have increased the fastest.

The six outcome reviews were consistent in concluding that there is specific support for Christian and Muslim forms of cognitive (and rational-emotive) psychotherapy for depression and anxiety. There is also preliminary evidence supporting the probably efficacy of a variety of other types of spiritually oriented psychotherapies, including a Christian devotional meditation intervention for anxiety, a Chinese Taoist CBT approach for anxiety, a Christian group treatment for unforgiveness, a Christian CBT approach for marital issues, a theistic spirituality group for eating disorders, and a Buddhist CBT approach for anger (Hook et al., 2010). However, because so few studies about these spiritually oriented psychotherapy approaches have been done, conclusions about their efficacy remain tentative. Studies are needed on a greater variety of spiritually oriented psychotherapies, with a greater variety of clinical issues, and with clients from a greater diversity of spiritual and cultural traditions.

\section{Methodological Limitations and Recommendations}

Each of the six outcome reviews noted methodological weaknesses that need to be corrected in future studies. Some of the most common weaknesses the reviewers noted included (a) small sample sizes; (b) failure to report attrition or a large percentage of attrition; (c) failure to randomly assign clients to treatment conditions; (d) no treatment manual or protocol; (e) no treatment fidelity checks; (f) failure to control for therapist effects; (g) failure to perform a long-term follow-up; and (h) failure to include clients from a greater diversity of religious, racial-ethnic, and cultural backgrounds. Several of the reviews also pointed out some of the methodological strengths of the outcome studies in this domain, including the frequent use of (a) experimental designs involving random assignment, control groups, and comparison of strict accommodation to secular psychotherapies; (b) real clients and real therapists in actual treatment settings; and (c) standardized outcome measures.

The methodological limitations of the studies on spiritually oriented psychotherapies are not uncommon in any psychotherapy outcome research. Nevertheless, given the current climate of managed care accountability and the evidence-based treatment movement, improvements in the quality of outcome studies about spiritual psychotherapies are clearly needed. Johnson (1993) described important methodological criteria, with which we concur, that psychotherapy outcome researchers should seek to achieve when evaluating spiritually oriented approaches with experimental studies, including (a) treatment manuals, (b) multiple therapists, (c) therapists trained to criteria, (d) evaluation of therapists' competence, (e) establishment of internal validity, (f) consistent verification of treatment integrity, (g) homogeneous subject samples, (h) clinical samples, (i) multiple channels of measurement, (j) evaluation of clinical significance, and (k) follow-up assessment.

\section{What Are We Most Concerned With: Type I or Type II Errors of Inference?}

Early in the study of spiritually oriented psychotherapy, researchers were concerned mostly with preventing Type II errors. Investigators wanted to see whether any effect existed when spiritually oriented approaches were used and/or when secular psychotherapies were religiously accommodated (i.e., reframed in religious terms) for religious clients. The first five reviews have established that some beneficial effects occur. Recently, attention has focused on providing more fine grained analysis to find out why such effects are occurring. Focusing on minimizing Type I errors-claiming an effect when it might not be veridical-by using conservative statistical assumptions and moderator analyses has recently been employed (Worthington et al., in press).

In 10 studies that compared strict accommodation and rigorous correction for any possibility of publication bias, Worthington et al. (in press) found that the mere inclusion of a spiritual component does not appear to be the critical factor in determining why a spiritually oriented effect exists (see Table 1). It may be that when a largely religious sample of clients participates in a secular 
Table 1

Major Findings and Conclusions of Six Reviews of Outcome Studies of Spiritually Oriented Psychotherapies (SOPs)

\begin{tabular}{|c|c|c|}
\hline Review article & $\begin{array}{c}\text { No. of studies and types of } \\
\text { SOPs }\end{array}$ & Major findings and conclusions \\
\hline $\begin{array}{l}\text { Worthington, Kurusu, } \\
\text { McCullough, \& } \\
\text { Sandage (1996) }\end{array}$ & $\begin{array}{l}\text { Total }=11(\text { SOCBT }=3 \\
\quad \text { SORET }=2, \text { SPGPI }=6)\end{array}$ & $\begin{array}{l}\text { Spiritually oriented cognitive and rational-emotive psychotherapies are effective with Christian } \\
\text { clients having mild depression, but only marginally more effective than secular versions; } \\
\text { quality of outcome research needs improving; more outcome studies are needed on various } \\
\text { types of SOPs; religious clients tend to prefer spiritually oriented approaches compared to } \\
\text { secular ones; there were few (and often methodologically limited) outcome studies of SOPs. }\end{array}$ \\
\hline McCullough (1999) & $\begin{array}{l}\text { Total }=5(\text { SOCBT }=3 \\
\quad \text { SORET }=2)\end{array}$ & $\begin{array}{l}\text { Spiritually oriented and secular cognitive and rational-emotive psychotherapies were equally } \\
\text { effective with Christian clients (mean effect size comparison between them was statistically } \\
\text { nonsignificant, though it slightly favored the SOPs, } d=.18, p=.34 \text { ); more outcome } \\
\text { studies are needed. }\end{array}$ \\
\hline $\begin{array}{l}\text { Worthington \& } \\
\text { Sandage (2001) }\end{array}$ & $\begin{array}{l}\text { Total }=9(\text { SOCBT }=7 \\
\quad \text { SORET }=2)\end{array}$ & $\begin{array}{l}\text { Spiritually oriented cognitive and rational-emotive psychotherapies were equally effective as } \\
\text { secular ones for Christian and Muslim clients with depression and anxiety (and in several } \\
\text { studies SOPs were more effective); outcome studies are needed with clients from other } \\
\text { religious traditions; studies needed on spiritually oriented marriage and family therapies; } \\
\text { effectiveness studies, not just efficacy studies, are needed. }\end{array}$ \\
\hline $\begin{array}{l}\text { Smith, Bartz, \& } \\
\text { Richards (2007) }\end{array}$ & $\begin{array}{l}\text { Total }=31(\text { SOCBT }=13 \\
\quad \text { SORET }=2, \text { SPGPI }=16)\end{array}$ & $\begin{array}{l}\text { Overall random-effects weighted average effect size for SOPs was } d=.56 \text {, which provides } \\
\text { moderately strong empirical support for their general effectiveness; specifically, Christian } \\
\text { and Muslim forms of cognitive and rational-emotive psychotherapy for religious clients } \\
\text { have received the most support; it appears that a variety of other SOPs may be effective, } \\
\text { but not enough studies have been done about any other specific approach to make confident } \\
\text { conclusions; more outcome studies are needed on a greater variety of SOPs with a greater } \\
\text { variety of clients; methodological improvements in the studies are needed. }\end{array}$ \\
\hline $\begin{array}{l}\text { Hook, Worthington, } \\
\text { Davis, Jennings, } \\
\text { Gartner, \& Hook } \\
\text { (2010) }\end{array}$ & $\begin{array}{l}\text { Total }=24(\text { SOCBT }=15 \\
\quad \text { SORET }=2, \text { SPGPI }=7)\end{array}$ & $\begin{array}{l}\text { Focus was on determination of empirically supported status; hence many studies were omitted } \\
\text { from consideration; in general, there is evidence that SOPs are efficacious (i.e., outperform } \\
\text { a control group and/or are equivalent to an alternative treatment) and that gains are } \\
\text { maintained at follow-up; however, the data base is small and some SOPs have no evidence } \\
\text { supporting their efficacy; no SOPs meet strict criteria for specificity (i.e., work better than } \\
\text { an alternative treatment), but more research is needed about this; SOPs with some evidence } \\
\text { supporting their efficacy are (a) Christian forms of CBT and RET for depression, (b) } \\
\text { Muslim forms of CBT for depression and anxiety, and (c) 12-step groups for alcoholism; } \\
\text { SOPs with some evidence supporting their possible efficacy are (a) Christian devotional } \\
\text { meditation, for anxiety, (b) Chinese Taoist CBT for anxiety, (c) Christian group treatments } \\
\text { for unforgiveness, (d) Christian CBT for marital issues, (f) spirituality group for eating } \\
\text { disorders, and (g) Buddhist CBT for anger; more effectiveness and specificity studies are } \\
\text { needed; methodological improvements are needed. }\end{array}$ \\
\hline $\begin{array}{l}\text { Worthington, Hook, } \\
\text { Davis, \& } \\
\text { McDaniel (in } \\
\text { press) }\end{array}$ & $\begin{array}{l}\text { Total }=61(\text { SOCBT }=21 \\
\quad \text { SORET }=2, \text { SPGPI }=43)\end{array}$ & $\begin{array}{l}\text { A rigorous approach was taken to analyzing the data; across all } 68 \text { independent samples from } \\
61 \text { studies, the overall mean pretest to posttest effect size }(d) \text { was .75; however, after } \\
\text { correcting for publication bias by imputing effect sizes that balance the finding that } \\
\text { published studies have higher effect sizes than unpublished using a "trim-and-fill" } \\
\text { procedure, the effect size fell to .49; across } 32 \text { samples where a SOP was compared with an } \\
\text { alternative treatment the mean effect size }(d) \text { was } .26 \text {, reduced to .16 using the statistically } \\
\text { conservative imputation of five effect sizes; using the highest level of standards for } \\
\text { psychotherapy research, which requires random assignment and equating a strictly } \\
\text { accommodated SO treatment with a secular treatment identical except for the SO } \\
\text { component, } 10 \text { studies were considered; the mean effect size }(d) \text { was .08, but when data } \\
\text { were imputed using trim and fill, the } d \text { fell to -..04; findings at follow-up were similar to } \\
\text { those at posttest; the authors concluded that taking the most conservative interpretation of } \\
\text { the findings, one would conclude that there is no reliable difference between a strictly } \\
\text { accommodated SOP relative to using the matched secular approach; however, there were } \\
\text { consistent positive effect sizes for the use of SOPs, so the authors suggested that SOPs are } \\
\text { having effects relative to alternative treatments and controls using even a conservative } \\
\text { statistical approach, but at this point, too few studies exist to describe exactly what the } \\
\text { differences are due to. }\end{array}$ \\
\hline
\end{tabular}

Note. Types of spiritually oriented psychotherapies investigated: SOCBT $=$ spiritually oriented Beck cognitive-behavioral therapy; SORET $=$ spiritually oriented rational-emotive therapy; SPGPI = spiritual practices/interventions (e.g., prayer, forgiveness, meditation, scripture reading, spiritual discussions, spiritual growth, spiritual guidance) combined with general psychological interventions (e.g., individual counseling, group counseling, marital counseling, psycho-education, stress management, progressive relaxation, lifestyle advice, body work, self-schema, body-mind-spirit, pastoral care, empathy, and couple enrichment).

intervention, it helps the clients despite being secular, not because of it. For example, a theologically conservative client might believe that his or her Scriptures teach that what people think in their heart is true. Such clients hear a secular description of CBT and automatically translate it into their religious system. They might, therefore, not differ from clients who hear the translation made explicitly in a religiously accommodated approach. The next challenge to psychotherapy researchers is to be vigilant to Type I errors 
to determine precisely where the effects actually reside in spiritually oriented or religiously accommodated secular treatments.

\section{Recommendations for a Methodologically Pluralistic Research Strategy}

Although we endorse the need for additional experimental outcome studies and for the improved rigor of these studies, we do not advocate a narrow definition of the criteria for what constitutes empirical support or evidence-based treatment. The APA's 2005 Policy Statement on Evidence-Based Practice in Psychology, which was published in the appendix of the APA Presidential Task Force on "Evidence-Based Practice in Psychology" report (APA, 2006), provides a helpful starting point for such an approach in that it encourages "the integration of the best available research with clinical expertise in the context of patient characteristics, culture, and preferences" (p. 284). It also avoids a narrow or rigid definition of what constitutes best research evidence. The APA Task Force on Evidence-Based Practice in Psychology report elaborates further concerning this concept:

Best research evidence refers to scientific results related to intervention strategies, assessment, clinical problems, and patient populations in laboratory and field settings as well as to clinically relevant results of basic research in psychology and related fields. APA endorses multiple types of research evidence (e.g., efficacy, effectiveness, cost-effectiveness, cost-benefit, epidemiological, treatment utilization) that contributes to effective psychological practice.

Multiple research designs contribute to evidence-based practice, and different research designs are better suited to address different types of questions. (p. 274)

The APA Task Force on Evidence-Based Practice in Psychology report lists and briefly describes various types of research designs and how they might contribute to evidence-based practice, including clinical observation (e.g., individual case studies), qualitative research, systematic case studies, single-case experimental designs, public health and ethnographic research, process-outcome studies, studies of interventions in naturalistic settings, randomized clinical trials (RCTs), and meta-analyses.

In our view, the APA Task Force on Evidence-Based Practice in Psychology report is a valuable document. It presents a brief history of the evidence-based practice movement and some of the controversy associated with it. It also provides a sophisticated, comprehensive perspective on evidence-based practice in psychology and the full range of evidence that needs to be considered when making decisions about patient treatment. In the spirit of wishing to encourage a thoughtful, comprehensive evidence-based approach to spiritually oriented psychotherapy practice, consistent with the APA report, we now briefly discuss several quantitative and qualitative research designs that have much potential for documenting the effects of spiritually oriented psychotherapies.

\section{Quantitative and Qualitative Research Designs}

Given that relatively few experimental therapy outcome studies (often called controlled clinical trials) of religious and spiritual therapies have been conducted, there is a need for more of them. Experimental outcome studies are time-consuming, expensive, and difficult to implement in actual treatment settings, but they are widely regarded as the premier design for demonstrating the causal efficacy of a treatment approach (Kazdin, 2003). Nevertheless, even carefully conducted experimental studies have limitations; most notably, (a) the difficulty of ruling out all possible threats to internal validity, (b) limited external (real life) validity, (c) limited generalizability beyond the specific sample used in the study, and (d) ethical concerns associated with the use of control groups. Thus, experimental outcome designs cannot be viewed as the final or infallible word concerning the efficacy of spiritually oriented psychotherapies.

Single- $N$ designs also have much potential for helping establish an evidence-base for spiritual psychotherapies. In a single- $N$ study, the client serves as his or her own control. By measuring changes in the client's symptoms or problems over time, the psychotherapists can see the impact of the treatment (Kazdin, 2003). Single- $N$ designs can have high ecological validity and they are often feasible for psychotherapists to use in clinical settings. These designs can also potentially demonstrate treatment effects of spiritual interventions and isolate the effects of specific spiritual components of treatment. A major disadvantage of single- $N$ designs is that they have limited internal validity and generalizability unless the design is repeated many times with many clients and psychotherapists.

Discovery-oriented and change process research designs also have potential for helping researchers understand and document significant change events during psychotherapy and their immediate and long-term impact on the process and outcome of treatment (Greenberg, 1986). Such designs are often clinically relevant and they can be helpful for understanding important spiritual change events in therapy and their influence on overall outcomes. They are also often feasible to carry out in clinical settings because they can be less intrusive and ethically problematic compared to experimental designs. A major weakness of discovery-oriented and change process designs is that they also have limited internal validity and generalizability unless they are repeated with many clients and psychotherapists.

From the qualitative research tradition, case study, ethnographic, and grounded theory designs also hold promise for providing rich insight into the spiritual nature and processes of psychotherapy and therapeutic change, as viewed from the perspectives of clients and therapists. Case studies have a long history in psychology and psychotherapy (Denzin \& Lincoln, 1994) and can provide qualitative evidence concerning the processes and outcomes of spiritual psychotherapies, although they cannot conclusively prove causation or rule out threats to internal validity. Additional weaknesses of case studies include questions about their generalizability and treatment outcomes are not quantitatively measured and documented.

Ethnographic and grounded theory studies, which may involve interviewing or participant observation of psychotherapy, clients, and/or psychotherapists, also may provide rich insight into clients' and psychotherapists' perceptions of the effects of spiritually oriented psychotherapies and the possible causal influences of the various components of such treatment approaches. The major disadvantages of ethnographic and grounded theory studies are their limited generalizability unless repeated with many clients and psychotherapists and the type and amount of change is not quantified. 
Qualitative studies are time-consuming, laborious, and are often challenging to report given the page limitations of journals. However, many of the methods used for data collection in qualitative research are similar to clinical methods (e.g., unstructured interviews, participant-observation, audiotaped conversations, field (case) notes, and diaries). Much of what therapists do in psychotherapy could yield data for qualitative studies.

We hope that during the next decade the effects and outcomes of spiritually oriented psychotherapies will be rigorously studied using both quantitative and qualitative methods. For readers who would like more information about these research designs, Richards and Bergin (2005, pp. 329-335) provided descriptions of the defining characteristics of quantitative and qualitative designs, their main strengths and weaknesses, the types of research questions that they are most suitable for investigating concerning spiritually oriented psychotherapies, as well as references to a number of helpful books on research design.

\section{Collaboration Between Practitioners and Researchers}

Psychotherapists in clinical settings can use the designs mentioned above to evaluate their own practices and to contribute to the establishment of a database on the outcomes of spiritual psychotherapies. This may be most feasible if practicing clinicians collaborate with scholars in academic and research settings. Collaboration between practitioners and academic researchers can bring the best of both worlds together-a treatment site where clinically relevant questions can and need to be investigated and the academic world where time, money, and support for conducting research is available. Both clinicians and scholars would benefit from such collaboration, and the database on spiritual psychotherapies would rapidly grow.

Research takes time and money, but although it can be challenging, research on spiritually oriented psychotherapies is more feasible today than it has ever been. When conducting quantitative studies, computerized and web-based outcome assessment systems and data analysis packages make data collection and analysis easier than it has ever been (e.g., Duncan, Miller, \& Sparks, 2004). Computerized assessment systems are helpful because they enable clients conveniently to complete the measures on the computer, which can simplify and speed up scoring, data analysis, and report writing. In addition, once clients take standardized assessments, it is possible to benchmark their performance and predict their likely response to treatment that is delivered within the practicing psychotherapists' offices against performance that has been demonstrated in controlled clinical trials. This method has been used a number of times (e.g., Minami, Serlin, Wampold, Kircher, \& Brown, 2008; Minami, Wampold, et al., 2008). Clients' test scores can be available for research purposes, and can also be provided in a timely fashion to clinicians for treatment planning and prognostication about clinical outcome. When conducting qualitative studies careful thought also needs to be given to how therapy sessions and/or research interviews will be recorded and transcribed. Fortunately, high quality video cameras, audio recorders, and transcribing software tools are available in today's world for relatively inexpensive prices.

\section{Assessing the Spiritual Outcomes of Spiritually Oriented Psychotherapies}

Until recently, clients' religious and (especially) spiritual functioning has not been assessed in psychotherapy outcome research as frequently as has mental health outcomes (Richards \& Bergin, 2005; Worthington et al., 1996). However, in recent years this has accelerated. Worthington et al. (in press) found that selecting the best standardized (if available) measure of religion (12 studies) and of spirituality (nine studies) showed that when spiritually oriented treatments were compared with controls, the treatments exceeded controls for religious outcomes but there were no differences between treatment and controls for nonreligious but spiritual outcomes. In our view, the current interest in spirituality as well as a continuing importance of religion calls for more attention to those outcomes.

It might seem odd to some people to assess religious and spiritual outcomes for either spiritually oriented or secular psychological treatments. However, in our view there are a number of compelling reasons why this should be done more frequently. First, religious and spiritual variables are not taboo to psychologists. Psychologists of religion routinely explore such variables, so they are legitimately a part of psychology. There are undoubtedly boundaries between religion and psychology, as stated in the resolution on psychotherapy and religion by the APA (2008). However certainly measuring religious and spiritual variablesand even targeting them for change in psychotherapy-is not off limits given that a psychologist is trained and competent to address the area. Second, many religiously committed people hesitate to seek psychotherapy from mental health professionals out of fear that it might undermine their religious faith and values (Richards \& Bergin, 2000; Worthington, 1988). Demonstrating which psychotherapies do not undermine faith and spirituality could help reassure many prospective clients, allowing access to treatment to some people who might otherwise eschew it. Third, if psychologists take religious and spiritual variables seriously and assess whether they are affected by psychotherapy, that focus could also increase the trust that leaders of religious communities have for mental health professionals and lead to greater numbers of referrals from them.

Fourth, assessing the religious and spiritual outcomes of spiritually oriented psychotherapies specifically could also help demonstrate whether a particular spiritual approach is equally effective with clients from different religious traditions, or whether it should only be used with clients from a limited number of denominations or faith traditions (Richards \& Bergin, 2000). Little is currently known about the ecumenical or multicultural sensitivity and effectiveness of the various spiritually oriented psychotherapies and so research investigating this is needed. Finally, assessing the religious and spiritual outcomes of spiritual psychotherapies could also help determine whether improvements in religious and spiritual functioning are associated with better treatment outcomes in other domains of clients' functioning. The possibility that spiritual growth may help promote and maintain other positive changes in clients' lives is worthy of further investigation.

Investigating the spiritual outcomes of psychotherapy can be challenging because there are relatively few religious and spiritual measures that have been used to date in psychotherapy outcome research, and none are available from commercial test publishers. 
Nevertheless, some measures are currently available and there are many other that await further validation in clinical settings. ${ }^{1}$ For example, the Spiritual Well-Being Scale (SWBS; Ellison \& Smith, 1991) has been used as a therapy outcome measure in a number of studies. It is brief and it correlates positively with a variety of physical and mental health indicators. Another promising measure is the Religious Commitment Inventory (RCI-10; Worthington et al., 2003). It measures "the degree to which a person adheres to his or her religious values, beliefs, and practices and uses them in daily living" (Worthington et al., 2003, p. 85). Factor analyses have revealed that the RCI-10 is composed of two subscales: (a) intrapersonal religious commitment and (b) interpersonal religious commitment. Evidence reported to date supports the validity and clinical usefulness of the RCI-10 with both Christian and nonChristian samples (Worthington et al., 2003).

Another recently developed measure is the 17-item Theistic Spiritual Outcome Survey (TSOS; Richards et al., 2005). The TSOS is grounded in a theistic view of spirituality and is in general harmony with the beliefs of many devout Christians, Jews, and Muslims. A factor analysis revealed that the TSOS is composed of three subscales: (a) Love of God, (b) Love of Others, and (c) Love of Self. Evidence to date has supported the use of the TSOS as a spiritual outcome scale in psychotherapy research, although additional validation work is still needed (Richards et al., 2005).

Other recently developed measures that may prove useful as spiritual outcome measures include the Spiritual Assessment Inventory (Hall \& Edwards, 1996) and Spiritual Transcendence Scale (Piedmont, 1999). More research in clinical settings is needed with these measures. In addition to validation studies of existing measures, new religious and spiritual measures created specifically for psychotherapy outcome research are needed.

\section{Caveats and Cautions}

Some scholars have argued that the "empirically supported treatment" movement is in danger of becoming an ideological and economic monopoly if it continues exclusively to use one philosophy of science (empiricism) and the quantitative research designs (experimental and single- $N$ ) favored by that philosophy (e.g., Slife, Hope, \& Nebeker, 1999; Slife, Wiggins, \& Graham, 2005). Although we agree that this is a danger, we think the APA Task Force on Evidence-Based Practice in Psychology guidelines and report (APA, 2006), if followed, will help reduce the likelihood of this occurring. Postmodern critiques of the natural and behavioral sciences have challenged exclusive reliance on experimental and quantitative research designs and have created space for a methodologically pluralistic approach. Qualitative, ethnographic, naturalistic, and phenomenological methodologies are being used with increasing frequency in the behavioral sciences, which in our view is fortunate because these approaches hold considerable promise for deepening professional understanding of the complexities and outcomes of psychotherapy and therapeutic change. A philosophically and methodologically pluralistic approach to outcome research on spiritually oriented psychotherapies will be most fruitful, not only for spiritual psychotherapies, but for the field as a whole (Slife et al., 1999, 2005).

It is also important for researchers investigating the outcomes of spiritually oriented psychotherapies to be aware that research methods that are based on the philosophical assumptions of scientific (reductive) naturalism may preempt the valid study of spiritual realities if careful thought is not given to prevent this (Slife et al., 1999; Slife \& Whoolery, 2006). Scientific naturalism is grounded in the philosophies of objectivism, materialism, and reductionism, and assumes, among other things, that a phenomenon is not real if it cannot be objectively observed and reduced into smaller parts (Slife \& Whoolery, 2006). When researchers start with reductive naturalism as their grounding assumption, the possibility that spiritual realities influence human behavior and welfare are ruled out of consideration, a priori, regardless of whether the methods are quantitative or qualitative. Slife and his colleagues (Slife et al., 1999; Slife \& Whoolery, 2006) argued that a philosophical and methodological pluralism that is open to the discovery of spiritual realities and influences in therapeutic change is needed.

Besides such caveats, ethical consideration and care is also needed in the use of spiritually oriented psychotherapies. For example, some psychotherapists and some religious people would draw firm boundaries altogether between religion and psychotherapy (West, 2000). More frequently, though, there is an acceptance that religion and spirituality are part of life and are often involved inextricably with each other. The APA ethical statement (APA, 2008) cautions psychologists to practice within their competency. If the clinician does not have training and supervised experience in dealing with religious issues, the clinician should-as with any multicultural area-refer to those who are qualified.

Even for trained and experienced psychologists, however, there are legitimate differences in belief about what is and is not appropriate-even with willing clients. For one example (and there are many), suppose a highly religious client seeks psychotherapy with a particular psychotherapist because (a) the psychotherapist is an adherent of the same faith as the client, (b) the psychotherapist has a reputation in the community of having successfully counseled numerous religious clients, and (c) the clergy person at the client's local place of worship refers the client specifically to that psychotherapist. When the first session begins, however, the client requests immediately that the psychotherapist pray aloud for the client. The psychotherapist might not believe this to be an ethical practice. Even if the client and psychotherapist agree, other observers (i.e., a supervisor, a member of the State Board of Psychologists, a partner in the group practice, or a person who reads a journal article describing this case-suitably disguised, of course) might see this as an inappropriate intrusion of psychotherapy into religion. Is it inappropriate? Is it something that violates the spirit of the APA (2008) resolution? There are legitimate (and sometimes debatable) ethical issues that deserve discussion but do not admit to complete consensus. Fortunately, there is a growing dialogue and increasing numbers of publications concerning ethical issues in this domain of psychological treatment (e.g., Gonsiorek, Richards, Pargament, \& McMinn, 2009; Hathaway \& Ripley, 2009). Psychotherapists need to be familiar with this growing literature to ensure that they use spiritually oriented approaches in an ethically sensitive manner.

\footnotetext{
${ }^{1}$ See Hill and Hood (1999) for a handbook that contains copies and critical reviews of over 120 measures of different types of religiousness and spirituality.
} 


\section{Conclusions}

Despite the progress that has been made much work remains to be done in this domain. There is still much that is not known or understood about spiritually oriented psychotherapies. For example, are spiritual psychotherapies in some situations more effective than secular one and, if so, when? What types of spiritual psychotherapies are most effective with what types of clients and problems? What types of spiritual psychotherapies do different types of clients prefer? When and how can specific spiritual interventions be implemented ethically and effectively? These and many other questions need further investigation (Hook et al., 2010; Richards \& Bergin, 2005; Worthington et al., in press).

For spiritually oriented psychotherapies to gain a place of equality and influence in the mainstream mental health professions, their claims need to be submitted to the scrutiny of empirical research. Without a more adequate empirical data base supporting their efficacy and specificity, there is a danger that spiritually oriented psychotherapies may be relegated permanently to the fringes of the mental health and medical fields. To ensure that this does not happen, outcome researchers and practitioners are needed throughout the world to assist with the development of a more adequate evidence-base for spiritually oriented psychotherapies. Clients may benefit the most if helping professionals and researchers succeed at this important task.

\section{References}

American Psychological Association. (2006). Evidence-based practice in psychology. American Psychologist, 61, 271-285.

American Psychological Association. (2008). Resolution on religious, religion-based and/or religion-derived prejudice. American Psychologist, 63, 431-434.

Ball, R. A., \& Goodyear, R. K. (1991). Self-reported professional practices of Christian psychologists. Journal of Psychology and Christianity, 10, $144-153$.

Denzin, N. K., \& Lincoln, Y. S. (Eds.). (1994). Handbook of qualitative research. Thousand Oaks, CA: Sage.

Duncan, B. L., Miller, S. D., \& Sparks, J. (2004). The heroic client: A revolutionary way to improve effectiveness through client-directed, outcome-informed therapy. San Francisco, CA: Jossey-Bass.

Ellison, C. W., \& Smith, J. (1991). Toward an integrative measure of health and well-being. Journal of Psychology and Theology, 19, 35-48.

Gonsiorek, J. C., Richards, P. S., Pargament, K. I., \& McMinn, M. R. (2009). Ethical challenges and opportunities at the edge: Incorporating spirituality and religion into psychotherapy. Professional Psychology: Research and Practice, 40, 385-395.

Greenberg, L. (1986). Change process research. Journal of Consulting and Clinical Psychology, 54, 4-9.

Hall, T. W., \& Edwards, K. J. (1996). The initial development and factor analysis of the Spiritual Assessment Inventory. Journal of Psychology and Theology, 24, 233-246.

Hathaway, W. L., \& Ripley, J. S. (2009). Ethical concerns around spirituality and religion in clinical practice. Washington, DC: American Psychological Association.

Hill, P. C., \& Hood, R. W. (1999). Measures of religiosity. Birmingham, AL: Religious Education Press.

Hook, J. N., Worthington, E. L., Davis, D. E., Jennings, D. J., Gartner, A. L., \& Hook, J. P. (2010). Empirically supported religious and spiritual therapies. Journal of Clinical Psychology, 66, 46-72.

Johnson, W. B. (1993). Outcome research and religious psychotherapies: Where are we and where are we going? Journal of Psychology and Theology, 21, 297-308.
Kazdin, A. E. (2003). Research design in clinical psychology (4th ed.) Needham Heights, MA: Allyn \& Bacon.

McCullough, M. E. (1999). Research on religion-accommodative counseling: Review and meta-analysis. Journal of Counseling Psychology, 46, 92-98.

Minami, T., Serlin, R. C., Wampold, B. E., Kircher, J. C., \& Brown, G. S (2008). Using clinical trials to benchmark effects produced in clinical practice. Quality and Quantity: International Journal of Methodology, $42,513-525$.

Minami, T., Wampold, B. E., Serlin, R. C., Hamilton, E. G., Brown, G. S., \& Kircher, J. C. (2008). Benchmarking the effectiveness of psychotherapy treatment for adult depression in a managed care environment: A preliminary study. Journal of Consulting and Clinical Psychology, 76, $116-124$.

Piedmont, R. L. (1999). Does spirituality represent the sixth factor of personality? Spiritual transcendence and the five-factor model. Journal of Personality, 67, 985-1013.

Raphel, M. M. (2001). The status of the use of spiritual interventions in three professional mental health groups. (Doctoral dissertation, Loyola College, Maryland, 2001). Dissertation Abstracts International, 62(2), 779A.

Richards, P. S., \& Bergin, A. E. (Eds.). (2000). Handbook of psychotherapy and religious diversity. Washington, DC: American Psychological Association.

Richards, P. S., \& Bergin, A. E. (2004). Casebook for a spiritual strategy in counseling and psychotherapy. Washington, DC: American Psychological Association.

Richards, P. S., \& Bergin, A. E. (2005). A spiritual strategy for counseling and psychotherapy (2nd ed.). Washington, DC: American Psychological Association.

Richards, P. S., \& Potts, R. W. (1995). Using spiritual interventions in psychotherapy: Practices, successes, failures, and ethical concerns of Mormon psychotherapists. Professional Psychology: Research and Practice, 26, 163-170.

Richards, P. S., Smith, T. B., Schowalter, M., Richard, M., Berrett, M. E., \& Hardman, R. K. (2007). Development and validation of the Theistic Spiritual Outcome Survey. Psychotherapy Research, 17, 643-655.

Shafranske, E. P. (2000). Religious involvement and professional practices of psychiatrists and other mental health professionals. Psychiatric Annals, 30, 525-532.

Shafranske, E. P., \& Malony, H. N. (1990). Clinical psychologists' religious and spiritual orientations and their practice of psychotherapy. Psychotherapy, 27, 72-78.

Slife, B. D., Hope, C., \& Nebeker, R. S. (1999). Examining the relationship between religious spirituality and psychological science. Journal of Humanistic Psychology, 39, 51-85.

Slife, B. D., \& Whoolery, M. (2006). Are psychology's main methods biased against the worldview of many religious people? Journal of Psychology and Theology, 34, 217-231.

Slife, B. D., Wiggins, B. J., \& Graham, J. T. (2005). Avoiding an EST monopoly: Toward a pluralism of philosophies and methods. Journal of Contemporary Psychotherapy, 35, 83-97.

Smith, T. B., Bartz, J. D., \& Richards, P. S. (2007). Outcomes of religious and spiritual adaptations to psychotherapy: A meta-analytic review. Psychotherapy Research, 17, 643-655.

Sperry, L., \& Shafranske, E. P. (Eds.). (2005). Spiritually oriented psychotherapy. Washington, DC: American Psychological Association.

Wampold, B. E., Mondin, G. W., Moody, M., Stich, F., Benson, K., \& Ahn, H. (1997). A meta-analysis of outcome studies comparing bona fide psychotherapies: "All must have prizes." Psychological Bulletin, 122, 203-215.

West, W. (2000). Psychotherapy and spirituality: Crossing the line between therapy and religion. Thousand Oaks, CA: Sage.

Worthington, E. L., Jr. (1988). Understanding the values of religious 
clients: A model and its application to counseling. Journal of Counseling Psychology, 35, 166-174.

Worthington, E. L., Jr., Hook, J. N., Davis, D. E., \& McDaniel, M. A. (in press). Religion and spirituality. In J. C. Norcross (Ed.), Relationships that work (2nd ed.). New York, NY: Oxford University Press.

Worthington, E. L., Jr., Kurusu, T. A., McCullough, M. E., \& Sandage, S. J. (1996). Empirical research on religion and psychotherapeutic processes and outcomes: A ten-year review and research prospectus. Psychological Bulletin, 119, 448-487.

Worthington, E. L., Jr., \& Sandage, S. J. (2001). Religion and spirituality. Psychotherapy, 38, 473-478.
Worthington, E. L., Jr., Wade, N. E., Hight, T. L., Ripley, J. S., McCullough, M. E., Berry, J. W., .. O O'Connor, L. (2003). The Religious Commitment Inventory-10: Development, refinement, and validation of a brief scale for research and counseling. Journal of Counseling Psychology, 50, $84-96$.

Received November 16, 2009 Revision received February 26, 2010 Accepted March 3, 2010

\section{Members of Underrepresented Groups: Reviewers for Journal Manuscripts Wanted}

If you are interested in reviewing manuscripts for APA journals, the APA Publications and Communications Board would like to invite your participation. Manuscript reviewers are vital to the publications process. As a reviewer, you would gain valuable experience in publishing. The $\mathrm{P} \& \mathrm{C}$ Board is particularly interested in encouraging members of underrepresented groups to participate more in this process.

If you are interested in reviewing manuscripts, please write APA Journals at Reviewers@apa.org. Please note the following important points:

- To be selected as a reviewer, you must have published articles in peer-reviewed journals. The experience of publishing provides a reviewer with the basis for preparing a thorough, objective review.

- To be selected, it is critical to be a regular reader of the five to six empirical journals that are most central to the area or journal for which you would like to review. Current knowledge of recently published research provides a reviewer with the knowledge base to evaluate a new submission within the context of existing research.

- To select the appropriate reviewers for each manuscript, the editor needs detailed information. Please include with your letter your vita. In the letter, please identify which APA journal(s) you are interested in, and describe your area of expertise. Be as specific as possible. For example, "social psychology" is not sufficient-you would need to specify "social cognition" or "attitude change" as well.

- Reviewing a manuscript takes time (1-4 hours per manuscript reviewed). If you are selected to review a manuscript, be prepared to invest the necessary time to evaluate the manuscript thoroughly. 